\title{
A PROVA PERICIAL NO FORO PENAL
}

\author{
José Lopes Zarzuela \\ Professor Doutor do Departamento de Medicina Forense e Criminologia \\ da Faculdade de Direito da Universidade de São Paulo
}

Resumo:

É apresentado um rol de conceitos de perícia no foro penal, esclarecendo-se que esta modalidade tem a peculiaridade de constituir uma atividade do Estado-juiz.

É reportada de forma extraordinária a evolução histórica da prova criminal de diversos povos, conforme as preleções do professor Rogério Lauria Tucci, destacando-se que o legislador penal dos anos 40 separou o exame de corpo de delito dos demais tipos de provas e consignando que Hélio Bastos Tornaghi considera que deveria retirar-se o exame de corpo de delito do capítulo das outras perícias previstas na processualística penal, situando-o entre a Prova e a Sentença.

\begin{abstract}
:
A list of concepts of examinations in the criminal court is presented, explaining that this aspect possesses the peculiarity of constituting an activity of the Judge state.

It is reported in a manner uncommon to the historic evolution of the criminal evidence of various countries, according to professor Rogério Lauria Tucci, pointing out that the criminal legislator of the 40's separated the examination of the body of the offense from the remaining types of evidence, trusting Hélio Bastos Tornaghi to consider removing the examination of the body of the offense from the chapter covering the other examinations foreseen in the criminal proceedings, placing it between the Proof and the Verdict.
\end{abstract}

\author{
SUMÁRIO \\ 1 Conceitos \\ a. Hélio Bastos Tornaghi \\ b. Moacyr Amaral Santos \\ c. Gabriel Rezende Filho \\ d. José Frederico Marques \\ e. Almeida Júnior e Costa Júnior \\ f. Zaccharias e Zaccharias \\ g. Guilherme Oswaldo Arbenz \\ h. Hernando Devis Echandia \\ i. Luigi Mattirolo \\ j. Ernest Desiré Glasson \\ k. Paul Kuche
}


1. João Bonuma

m. João Manuel de Carvalho Santos

n. Jorge Americano

o. José Lopes Zarzuela

2 - A Perícia no âmbito do Processo Penal

3 - Escorço Histórico da Perícia Penal

a. China

b. Israel

c. Grécia

d. Roma

e. Direito Canônico

f. Da Idade Média à Atualidade

g. Portugal

h. Brasil

4 Natureza Jurídica

5 Modalidades de Perícias no Foro Penal

a. Percipiendi

b. Deduciendi

c. Direta

d. Indireta

e. Contraditórias

f. Complementares

g. Retrospectiva

h. Prospectiva

\section{1 - CONCEITOS}

a. Hélio Bastos Tornaghi: Perícia constitui uma pesquisa que exige conhecimentos técnico, científico ou artísticos.

b. Moacyr Amaral Santos: Perícia consiste no meio pelo qual, no processo, pessoas entendidas e sob compromisso verificam fatos interessantes à causa, transmitindo ao juiz o respectivo parecer.

c. Gabriel de Rezende Filho: Perícias não são senão meios de prova, consistindo na inspeção judicial feita por perito sobre pessoas, coisas, móveis etc., para verificar algum fato ou circunstância ao mesmo relativa. 
d. José Frederico Marques: Perícia é uma prova destinada a levar ao magistrado elementos instrutórios sobre normas técnicas e sobre a prova do fato que dependa de conhecimentos especializados.

e. Almeida Júnior e Costa Júnior: Perícia é toda atuação de técnicos ou doutos, promovida pela autoridade competente, com a finalidade de esclarecer a Justiça sobre um fato de natureza permanente ou duradouro. Quando esta atuação é incumbência de médico, nomeado legalmente para esse mister, chamamô-la perícia médica.

f. Zaccharias e Zaccharias: Perícia é o exame que, por determinação da autoridade policial ou judiciária, realiza-se com a finalidade de elucidar fato ou evidenciar estado ou situação no interesse da Justiça.

g. Guilherme Oswaldo Arbenz: Perícia é toda a operação ordenada por autoridade judiciária ou policial, que se destina a ministrar esclarecimentos técnicos à Justiça.

h. Hernando Devis Echandia: Perícia é uma atividade processual desenvolvida em virtude de encargo judicial, por pessoas distintas das partes do processo, especialmente qualificadas por seus conhecimentos técnicos, artístico ou científico, mediante o que são ministrados ao juiz argumentos ou razões para formação de seu convencimento sobre certos fatos cuja percepção ou cujo atendimento escapa das aptidões comuns das pessoas.

i. Luigi Mattirolo: Perícia é o testemunho de uma ou mais pessoas peritas para o conhecimento de um fato, cuja existência não pode ser averiguada ou juridicamente apreciada sem o concurso de especiais conhecimentos científico ou técnico.

j. Ernest Desiré Glasson: Perícia é a operação conferida a certas pessoas, em razão de seus conhecimentos especiais sobre os fatos que os juízes, por si próprios, não poderiam apreciar com exatidão.

k. Paul Kuche: Perícia consiste na atribuição conferida a pessoas competentes; tendo em vista a solução da causa de proceder a verificações, que exigem conhecimentos especiais e comunicar ao tribunal o resultado do seu exame.

1. João Bonuma: Perícia é a contribuição fornecida ao juiz por um terceiro, nomeado ad hoc ou investido em tais funções em virtude de cargo, para a verificação de fatos ou suas consequiências relativamente à demanda.

m. João Manuel de Carvalho Santos: Perícia consiste no encargo conferido a pessoas competentes, de preferência especializadas e técnicas, para 
proceder às averiguações que se fizerem necessárias, para o esclarecimento das questões debatidas no processo, sempre que tais pronunciamentos exijam conhecimentos especializados, devendo o resultado do exame procedido ser levado ao conhecimento do juiz, por meio do laudo.

n. Jorge Americano: Perícia se verifica toda vez que o juiz confia a pessoas técnicas, sob compromisso, o ofício de examinar e dar opinião sobre uma questão de fato que exige conhecimentos especializados.

o. José Lopes Zarzuela: Perícia é uma modalidade de prova que requer conhecimentos especializados para a sua produção, relativamente à pessoa física, viva ou morta, e à coisa, implicando na apreciação, interpretação e descrição de fatos ou de circunstâncias de presumível ou de efetivo interesse judiciário.

\section{A perícia no âmbito do Processo Penal}

Tem a peculiaridade de constituir uma atividade estatal destinada a fornecer elementos instrutórios de ordem técnica e proceder a comprovação e formação do corpo de delito. A perícia consumada na fase preparatória do inquérito policial, não representa simples peça investigatória, apesar de prestar-se para integrar a informatio delicti. Ultimada em qualquer fase do procedimento penal, é sempre ato instrutório de órgão auxiliar da justiça na pesquisa da verdade. Seu valor é o mesmo, tanto ao ser procedida em juízo, quanto ao ser realizada durante a fase preparatória do inquérito. Sua força probatória deriva da capacidade técnica do perito que elabora o laudo, bem como do conteúdo desse trabalho.

\section{Escorço histórico da perícia penal}

a. China. Conforme preleciona o professor Rogério Lauria Tucci na obra Do Corpo de Delito no Direito Processual Penal Brasileiro, São Paulo, Saraiva, 1978, no código chinês Ta-Tsing-Len-Lee, há registros de lesões corporais e cálculos do tempo que tais ferimentos levam para a recuperação da vítima; a descrição dessas lesões implicava na realização do exame de corpo de delito no ofendido, sugerindo que a perícia médica tinha como escopo a determinação da materialidade do fato como pressuposto do processo.

$\mathrm{Na}$ China, Egito e outros países orientais, as impressões papilares foram utilizadas para substituir a assinatura de analfabetos e na identificação de 
delinqüentes. Verifica-se assim que esta modalidade de identificação constituiu a ancestral dos modernos arquivos monodactilares, destinados exclusivamente à guarda de dactilogramas de criminosos, bem como os dactilogramas artificiais revelados e levantados nos locais do fato.

b. Israel. João Mendes de Almeida Júnior esclarece que desde as mais longínqüas épocas da história, o exame de corpo de delito foi a mais importante das perícias, realizada com a presença da autoridade judiciária no local do fato; esta, através da inspeção ocular, procedia o exame pericial, particularmente nas ocorrências de homicídios, lesões corporais e crimes contra os costumes. No Deuteronômio há menção do exame de corpo de delito direto nos homicídios, a fim de se apurar a responsabilidade penal do acusado, referindo-se também ao exame de corpo de delito indireto em casos de envenenamento, casos estes em que participava o Conselho de Varões, aos quais se dava a incumbência de coletar elementos instrutórios para provar o fato perante os juízes.

c. Grécia. Na colheita das provas havia um procedimento misto: inicialmente procedia-se a acusação por qualquer pessoa do povo e depois era realizada a inquirição das testemunhas, cabendo ao acusador a produção das provas que eram submetidas à apreciação da suprema assembléia. Não faltou aos gregos a acurada percepção do fato criminoso, diretamente pela intervenção de técnicos e indiretamente por testemunhas. Em Atenas, no julgamento do homicídio aplicava-se um misto de cognição do arconte ou do conselho dos técnicos e do depoimento de testemunhas. Ao órgão judicante cabia a apreciação valorativa dos elementos coletados, seguindo-se-lhe a prolatação da sentença.

d. Roma. Entre os romanos havia a necessidade de fixar-se a materialidade do crime para só então cogitar-se imputá-lo ao seu autor. Todavia, este aspecto não é pacífico, pois, segundo David Winspeare e Nicola Nicolini, não era costumeira a constatação existencial do delito independentemente da apuração de seu responsável. No procedimento penal da accusatio, empregado desde o fim da república romana, no sistema processual das quaestiones perpetuae, quem pretendesse sustentar uma acusação, deveria oferecer libelo no qual teria que ser indicado o delito praticado e a lei que fora violada, impondo-se ao acusador juramento sobre o que afirmasse ser verdadeiro. Com o somatório desses elementos passava-se a analisar os meios probatórios oferecidos pelo delator, com ou sem auxílio de órgãos públicos. Este conjunto probatório correspondia a uma atividade totalmente similar à preparação do inquérito policial de nossos dias. Passava-se 
depois a inquisitio, destinada a apuração da infração penal, a fim de comprovar-se sua materialidade, isto é, à formação do corpo de delito, para que se pudesse fundamentar a acusação e a prolatação da sentença. No processo penal romano distinguiam-se três períodos perfeitamente distintos:

- comicial, fundamentado na inquisitio e caracterizado pela ausência de formalidades procedimentais. Empregava-se a coercitio e a anquisitio, em que a coletividade se fazia juiz dos próprios interesses, instituindo-se em órgão judicante ou delegando a repressão a agentes estatais;

- procedimento ordinário das quaestiones, caracterizada pela accusatio;

- extraordinaria cognitio depois de restaurado o procedimento penal de ofício. Nestes períodos prevaleceu o procedimento inquisitório, parecendo que somente se procedia contra o indiciado a inquisitio. A ação penal era realizada pelo inquisitor que, apesar da liberdade que dispunha só podia acionar o responsável desde que contra o mesmo existissem elementos probatórios de sua culpabilidade. Portanto, só depois de plena segurança da existência do fato punível é que a autoridade encarregada da persecutio criminis iniciava a ação penal, a fim de imporlhe a pena compatível com o delito cometido, observando-se no processo penal romano o princípio segundo a qual actio non datur nise constet de crimini.

e. Direito Canônico. Os tribunais eclesiásticos foram preliminarmente dominados pelo princípio acusatório, constituindo a acusação o modus ordinarius destituído de qualquer concepção inovadora, considerando que foi plenamente inspirado no Direito Romano. Diante da necessidade de estabelecer-se um procedimento mais severo, o papa Inocêncio III introduziu o sistema consubstanciado na persecutio ex officio que se denominou per inquisiotionem. Estabeleceu-se então que além da acusação, o procedimento criminal deveria ser iniciado através do inquérito ou por denúncia. Este procedimento desenrolava-se em uma das seguintes modalidades: per accusationem ou per denunciationem ou per inquisitionem.

O papa Inocêncio III introduziu no processo penal canônico o emprego da inspeção ocular pelo juiz e a perícia médica, com a finalidade da apreciação e fixação do corpo de delito. Com a evolução da medicina na Idade Média, os peritos passaram da simples inspeção externa do cadáver para também a interna, através da abertura de suas cavidades naturais. 
f. Da Idade Média à Atualidade. Foi o direito canônico que difundiu a regra de que a comprovação do corpo de delito no crime de homicídio deveria ser ultimada pelo juiz e pelo perito médico, estendendo-se depois tal regra a todos os delitos perpetrados contra a integridade física do ofendido.

Nos direitos germânico e anglo-saxônico tal atividade era exercida pelo juiz e pelo coroner. Em todos os casos de encontro de cadáver era usual comprovar-se o fato in genere, ou seja, o corpo de delito.

Os jurisconsultos italianos do século XIV e os práticos napolitanos do século $\mathrm{XV}$, adotaram que o corpo de delito representava o fundamento do processo penal. Tal preceito nos séculos futuros estendeu-se a toda a instrução criminal.

Próspero Farinácio empregou a expressão corpus delicti pela primeira vez na obra Quaestiones $I$ e, posteriormente, com as idéias consagradas nas revoluções francesa e norte-americana, aparece nova concepção procedimental no código napoleônico, onde se fundiram elementos dos procedimentos inquisitório e acusatório. As regras relativas à constatação do corpo de delito dizem respeito ao momento introdutório da persecutio criminis, com a adoção do imperativo actio non datur nisi constet de corpore delicti.

Nas legislações austríaca de 1859, alemã de 1877 , bem como na belga, espanhola, britânica, italiana e portuguesa, apareceram normas correlatas, observando-se em todas a preocupação de realizar-se a comprovação da materialidade do delito, a fim de impor-se a perseguição e sanções punitivas ao autor da infração penal.

g. Portugal. A primeira lei que se referiu à materialidade do crime, data de meados do século XIV, dispondo sobre o regime da prova do crime de lesões corporais no Livro das Leis e Posturas.

Nas Ordenações Afonsinas há igualmente dispositivos de conteúdo penal no livro $\mathrm{V}$, alusivos a comprovações de ferimentos, particularmente nos títulos VI, XXXIV, LXXXII e CX, disposições estas baseadas em fontes históricas do Livro das Sete Partidas e no Fuero Real de Afonso X, o Sábio. As Ordenações Manuelinas mencionam nos capitulos XLII, LXVIII e LXXV do livro V, provas sobre lesões, inquirição contra autor de delito de cárcere privado, comprovação de ferimentos, espancamentos e defloramento. As Ordenações Filipinas, como as precedentes, dispuseram nos livros I e V, respectivamente nos títulos LXV, XCV e CXVII, sobre as devassas particulares e a verificação prévia de lesões corporais bem como da menção do procedimento inquisitivo. Além das Ordenações do Reino foram 
editados atos legislativos relativos ao corpo de delito, como a lei de 6 de dezembro de 1612 e o alvará de 20 de outubro de 1763; na lei de 1612, chamada de Reformação da Justiça, assinala-se que sem o corpo de delito, o procedimento criminal não poderia subsistir. Todavia, no alvará de 1763, aparentemente é registrada pela primeira vez a expressão corpo de delito. Tal locução é mencionada no alvará de 1765 , relativamente ao processo criminal militar e no alvará de 1810 , relativo à determinação da intervenção de médicos nos exames periciais, nomeados na qualidade de legistas. O Assento da Relação do Porto, de 20 de novembro de 1760 , contém as providências que deveriam ser adotadas no local de exame de pessoas feridas, bem como a menção de que especialidade médica deveria participar desses exames.

h. Brasil. Na legislação editada no Império, a primeira referência à locução corpo de delito aparece nas instruções de 4 de novembro de 1825 , determinando que os comissários de polícia deveriam dirigir-se ao local onde houvesse ocorrido encontro de cadáver ou pessoa ferida; deveriam arrolar testemunhas, apreender armas e outros instrumentos de crime como peças de instrução para servirem ao procedimento legal e oferecerem ao juiz todas as informações necessárias. O juiz criminal era o perito a quem competia a inspeção do local e a formação do corpo de delito. Esta regra processual foi posteriormente reproduzida no art. 134 do código de processo criminal de 1832, com a especificação do auto de corpo de delito. $\mathrm{O}$ art. 158 do CPP vigente teve sua redação provavelmente inspirada no conteúdo da disposição legal contida no código de processo criminal de Primeira Instância do Império do Brasil, ao registrar a indispensabilidade da formação do auto de corpo de delito, tanto nas perícias diretas, através da inspeção ocular, quanto através de testemunhas, como fundamento do procedimento penal, sendo nulo o processo criminal em sua ausência, não podendo supri-lo, inclusive, a confissão do acusado. A Lei n. 261, de 3 de dezembro de 1841, no art. 47 textua que nos crimes que não deixam vestígios, ou de que se tiver notícia quando os vestígios já não existam e não se possam verificar ocularmente por um ou mais peritos, poder-se-á formar o processo independentemente de inquirição especial para o corpo de delito, sendo no sumário inquiridas testemunhas, não-só a respeito da existência do delito e suas circunstâncias, como também acerca do delinqüente. $O$ regulamento n. 120, de 31 de maio de 1842, dispõe no art. 256 sobre a necessidade de realizar-se imediatamente o corpo de delito, quando da prática de crimes que deixam vestígios, observando-se o texto dos arts. 136 e 137 do código de processo 
criminal. Outros dispositivos legais que se seguiram transferiram a atribuição de comprovação do corpo de delito, que era atribuição privativa do juiz criminal, para o chefe de polícia, delegado e subdelegado de polícia, juiz municipal e juiz de paz.

Com o advento da República, por determinação constitucional, a competência a respeito de legislação processual foi delegada aos Estados-Membros da União. O Estado de São Paulo editou o código de processo penal, fruto de esforços de João Mendes de Almeida Júnior. Este código, no art. 169 textuava: "quando tiver sido cometido algum delito que deixe vestígios, que possam ser ocularmente examinados, a autoridade policial, ou o juiz de paz que mais próximo e pronto se achar, a requerimento da parte, ou de oficio, nos crimes em que teve lugar a denúncia, procederá imediatamente o corpo de delito"

Com o advento da Constituição Federal, de 16 de julho de 1934, restabeleceu-se a competência privativa da União para legislar sobre matéria processual. O governo federal instituiu comissão formada por Antonio Bento de Faria, Plínio de Castro Casado e Luiz Barbosa da Gama Cerqueira, presidida pelo então ministro da Justiça e Negócios Interiores, Vicente Rao, a fim de apresentarem projeto do novo CPP, o que foi efetivamente ultimado em 15 de agosto de 1935, encontrando-se no mesmo disciplinado o exame de corpo de delito no título IX Das Provas, arts. 219 a 223, com as características tradicionais.

Em decorrência do golpe de Estado de 10 de novembro de 1937, este projeto não foi encaminhado para discussão e votação, tendo outra comissão sido formada por Vieira Braga, Nélson Hungria, Narcélio de Queiroz, Roberto Lyra e Cândido Mendes de Almeida. Cuidou o novo projeto do CPP do exame de corpo de delito, no capítulo das perícias em geral, transformando-se no CPP vigente pelo Decreto-lei n. 3.689, de 3 de outubro de 1941, com vigência a partir de $1^{\circ}$ de janeiro de 1942.

4 Natureza jurídica

O legislador do CPP vigente dispôs o exame de corpo de delito e as perícias em geral no início da parte do código, no título Das Provas, demonstrando assim dois aspectos essenciais:

a. considerar que o exame de corpo de delito constitui uma modalidade de perícia; 
b. atribuir ao exame de corpo de delito um valor particular.

Entretanto, não é pacífica a concepção de perícia entre os processualistas, pois, enquanto alguns a considerem modalidade de prova, outros a consideram mais do que prova, levando em conta que a perícia possui tudo o que se exige de um meio de prova, mas contém ainda outros elementos não contidos na mesma, razão pela qual a inserem entre a Prova e a Sentença. Pode-se afirmar que não é raro que o juiz, ao tomar conhecimento de um fato, passe a apreciá-lo, objetivando fundamentar as pretensões do autor e a oposição do réu. $\mathrm{Na}$ ausência de conhecimentos técnico, científico ou artístico para formar seu convencimento a respeito de determinado caso, não tem o magistrado condições de avaliar o fato, objeto do conflito de interesses, motivo pelo qual tem que se amparar no conhecimento especializado do perito. Se este se limitasse a apresentar ao juiz simplesmente o que apurou, tornaria a perícia apenas um mero instrumento de prova.

Todavia, como o perito emite juízos de valor dos fatos que analisa e oferece sua opinião técnica, científica ou artística, sobre como tais fatos foram produzidos e de terem provocado determinados efeitos, obviamente o perito se vale de princípios de experiência, demonstrando as possíveis relações do fato analisado com outros eventos. O perito não se restringe em relatar ao juiz o que ocorreu e do que tem consciência em função de seu conhecimento especializado, mas também quais as possíveis conseqüências dos fatos que apreciou e interpretou. Deste modo, o diagnóstico e, muitas vezes, o prognóstico emitido pelo perito não podem ser simplesmente vistos como meios de prova. A perícia constitui um misto de apreciação, interpretação e declaração, o que implica dizer que, além de analisar elementos objetivos do fato, introduz um componente subjetivo representado pela valoração. $\mathrm{O}$ juiz avoca a testemunha porque conhece o fato e requer a participação do perito para que o conheça; enquanto a testemunha recorda, o perito relata. Pela destacada importância que apresenta, a perícia constitui um meio instrumental técnico-opinativo e alicerçador da sentença; é meio instrumental porque, como todos os atos processuais, representa um instituto eficaz de que se pode valer o juiz para a solução da lide, cujo escopo consiste na declaração da existência, ou não, do direito pleiteado. A perícia se justifica sempre que há necessidade da emissão de uma opinião fundamentada sobre um determinado fato, representando uma pesquisa que é depois transformada em juízo valorativo. Apesar do sistema legislativo processual brasileiro não vincular o juiz à perícia, o magistrado, de plano, só poderá rejeitá-la por erro culposo ou doloso, sendo que, neste último caso, caberá inclusive sanções 
penais ao perito por crime contra a administração da justiça previsto nos arts. $342 \mathrm{e}$ 347 do CP.

Segundo Hélio Bastos Tornaghi seria acertado retirar a perícia do capítulo das provas e situá-la em outro independente, entre a prova e a sentença, particularmente levando-se em conta que o legislador não colocou o perito entre os sujeitos da prova, dele tratando no mesmo título em que disciplina a atividade do juiz e do membro do Ministério Público, onde todos estão igualmente sujeitos à disciplina judiciária e estendendo-lhe o disposto sobre suspeição e impedimentos aplicáveis aos juízes, no que couber.

É interessante lembrar que antes do estabelecimento da competência legislativa, sobre direito processual, passar dos Estados para a União, o Código de Processo Penal do Distrito Federal (Decreto-lei n. 16.751, de 31 de dezembro de 1924), não colocava a perícia entre os meios de prova e sim no título VI - Atos Preliminares da Ação Penal.

5 Modalidades de perícias no âmbito penal

Diversos são os critérios classificatórios das perícias:

a. Perícias Percipiendi. Constitui a retratação técnica ou científica das percepções colhidas pelo perito restrita à apreciação de fatos ou de circunstâncias, desacompanhadas da emissão de juízos valorativos.

b. Perícias Deduciendi. Consiste na apreciação e interpretação técnica ou científica de fatos ou de circunstâncias, com a emissão de juízos valorativos.

c. Perícia Direta. É a realizada sobre elementos constitutivos do corpo de delito. Representa o exame feito no cadáver, na folha da porta cujo sistema de segurança foi violado, nas manchas de sangue encontradas no piso, no encontro de peças ósseas em terreno baldio, etc. Esta modalidade de perícia é baseada no imperativo legal contido no art. 158 do CPP.

d. Perícia Indireta. É a realizada para suprir a perícia direta, quando os elementos constitutivos do corpo de delito desapareceram, situação que o perito deverá contornar procedendo à reconstrução de seus vestígios através de elementos contidos nos autos e dos que resultarem das diligências processuais ultimadas. Esta modalidade de perícia está prevista nos arts. 158 e 172, §único do CPP Como se depreende do texto do art. 167, quando não há absolutamente nenhuma possibilidade 
de realização do exame de corpo de delito, direto e indireto, é que a prova testemunhal poderá suprir-lhes a ausência.

e. Perícias Contraditórias. São aquelas realizadas por diferentes peritos sobre a mesma matéria, nas quais há conclusões divergentes, segundo os critérios de apreciação e interpretação dos elementos colhidos por cada um dos peritos. Esta modalidade de perícia está prevista nos arts. 180 e 182 do CPP e 436 e 437 do CPC, que oferecem aos juízes criminais e cíveis as regras básicas para solucionarem as discrepâncias apresentadas nos laudos periciais.

f. Perícias Complementares. Perícia complementar é outra ou outras destinadas a completar a primeira por mostrar-se omissa, obscura, inexata, de conteúdo contraditório ou deficiente, inobservando formalidades processuais ou ultimada para a classificação médico-legal classificatória do crime de lesões corporais. Esta modalidade de perícia está prevista nos arts. $168, \S \S 1^{\circ}$ e $2^{\circ}$ e 181 do CPP e 439 do CPP A análise dos arts. 168, $\S 1^{\circ}$, I do CPP e 129, $\S 1^{\circ}$, I do CP, permitem concluir que podem ocorrer as seguintes situações:

- inobservância de formalidades, existência de obscuridades, de contradições, de erros culposos ou de omissões;

- classificação médico-legal do crime de lesões corporais, através de exame complementar realizável trinta dias após a data da prática do delito.

g. Perícias Retrospectivas. São aquelas realizadas no presente sobre fatos ocorridos, próxima ou remotamente, a fim de projetá-los ao futuro para que produzam efeitos jurídicos.

h. Perícias Prospectivas. São aquelas realizadas no presente nas quais se fazem prognósticos sofre efeitos futuros. Estas perícias permitem, pela análise de determinados aspectos, avaliar situações futuras, como ocorre com a perícia de verificação da cessação ou da persistência da periculosidade do condenado. 


\section{BIBLIOGRAFIA}

ALMEIDA, J. C. M. A. de. Principios fundamentais do processo penal. São Paulo : Revista dos Tribunais, 1973.

ALMEIDA JR, A. F. e COSTA JR, J. B. O. e. Lições de medicina legal. $20^{\mathrm{a}}$ ed. São Paulo : Nacional, 1991.

ARBENZ, G. O. Medicina legal e antropologia forense. Rio de Janeiro : Atheneu, 1988.

BRASIL, LEIS, DECRETOS etc. Código de processo penal. $26^{\mathrm{a}}$ ed. São Paulo : Saraiva, 1987.

DEVIS ECHANDIA, H. Teoria general de la prueba judicial. $15^{\mathrm{a}}$ ed. Buenos Aires : Victor de Zavaglia, 1981.

ESPÍNOLA FILHO, Eduardo. Código de processo penal anotado. $6^{\mathrm{a}}$ ed. Rio de Janeiro : Borsoi, 1965.

MARANHÃO, O. R. Curso básico de medicina legal. $6^{\mathrm{a}}$ ed. São Paulo : Malheiros, 1991.

MOURA, M. T. R. A. A prova por indícios no processo penal. São Paulo: M. T. R. A. M., 1981. Dissertação (mestrado FDUSP).

QUINTANA REYES, L. La prueba en el procedimiento canonico. Barcelona : Bosch, 1943.

ROSA, E. Dicionário de processo penal. Rio de Janeiro : Rio, 1975.

SANTOS, M. A. Prova judiciária no cível e no comercial. $12^{\mathrm{a}}$ ed. São Paulo : Max Limonad, v. 5, 1975.

SILVA, De P. e. Vocabulário jurídico. $3^{\mathrm{a}}$ ed. Rio de Janeiro : Forense, 1991.

SOUZA LIMA, A. J. Tratado de medicina legal. $5^{\text {a }}$ ed. Rio de Janeiro : Freitas Bastos, 1933.

SURGIK, A. Compêndio de direito processual canônico. Curitiba : Livro é Cultura, 1988.

TORNAGHI, H. Instituições de processo penal. $2^{\mathrm{a}}$ ed. Rio de Janeiro : Konfino, 1978.

TUCCI, R. L. Do corpo de delito no direito processual penal brasileiro. São Paulo : Saraiva, 1978.

VENTURA, P R. L. Direito processual penal resumido. Rio de Janeiro : Rio, 1974. 